\title{
A Case of Aortic Dissection Complicating Right Subclavian Artery Occlusion and Mimicking Inferior Myocardial Infarction
}

Ahmet Doksöz' , Müjgan Tek Öztürk², Wesam Salha', Murat Taraktaş³, Hüseyin Soydemir ${ }^{4}$

'Department of Cardiology, Gebze Medikal Park Hospital, Kocaeli, Turkey

2Department of Cardiology, Keçiören Training and Research Hospital, Ankara, Turkey

32Department of Cardiology, Private Ümit Hospital, Eskişehir, Turkey

4Department of Cardiovascular Surgery, Medikal park Tokat Hospital, Tokat, Turkey

\begin{abstract}
Introduction: Acute aortic dissection is the most common catastrophic event affecting the aorta. Aortic dissection can present with a wide range of manifestations and is easily misdiagnosed.

Case Report: Here we report a case of aortic dissection that was initially misdiagnosed as inferior wall myocardial infarction although the initial symptoms were related to right subclavian artery occlusion caused by a dissection flap. Aortic dissection was diagnosed after the patient underwent coronary angiography. The patient was managed with immediate surgical repair and was discharged in a stable condition.

Conclusion: This case report illustrates the importance of having a high index of suspicion for aortic dissection to avoid a mistaken diagnosis in patients with an electrocardiogram (ECG) suggestive of ST elevation myocardial infarction (STEMI).
\end{abstract}

Key words: Aortic dissection, myocardial infarction, subclavian artery occlusion

Received: 11.07.2016 Accepted: 07.09.2016 Available Online Date: 03.11.2016

\section{Introduction}

Aortic dissection (AD) is defined as the separation of layers within the aortic wall. Tears in the intimal layer result in the propagation of dissection (proximally or distally) secondary to the entry of blood into the intima-media space. Acute aortic dissection is an extremely severe condition having a high risk of mortality. The classic symptom may mimic other conditions such as myocardial ischemia, leading to misdiagnosis. Coronary malperfusion associated with aortic dissection is relatively rare, but when it occurs, it may be fatal to the patient. Up to $30 \%$ of patients suffering from aortic dissection are initially suspected of having other conditions (1). Here we report a case of initially misdiagnosed acute aortic dissection in which a dissection flap occluded the ostium of the right coronary artery and right subclavian artery. Written informed consent was obtained from patient.

\section{Case Report}

A 62-year-old female with a medical history of hypertension was referred to emergency service because of chest and right upper extremity pain and syncope. Her initial vital signs showed blood pressure of 100/60 $\mathrm{mmHg}$ and heart rate 80 beats $/ \mathrm{min}$. ECG at admission showed ST elevation in the inferior leads (Figure 1). Emergent coronary angiography was performed. Coronary angiography revealed an ascending aortic dissection with normal coronary arteries (Figure 2,3).

A bedside transthoracic echocardiogram was also performed and showed a dilatation of the ascending aorta with an evidence of intimal tear and moderate aortic regurtation. The vascular surgery team was immediately consulted, and the patient was transferred for emergency surgery. The Bentall procedure was performed. 


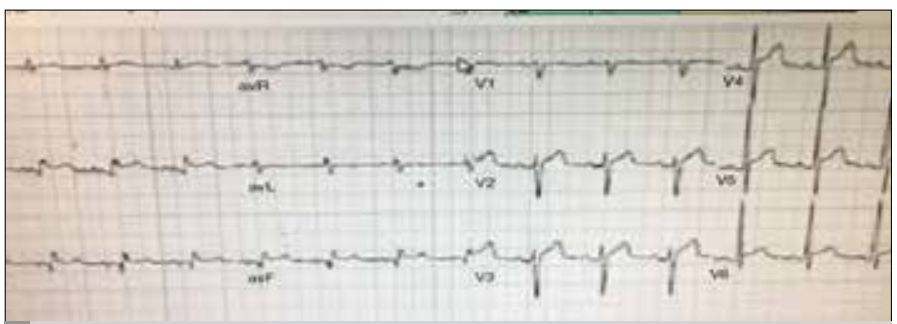

FIGURE 1. Twelve-lead electrocardiogram (ECG) showing ST segment elevations in inferior leads

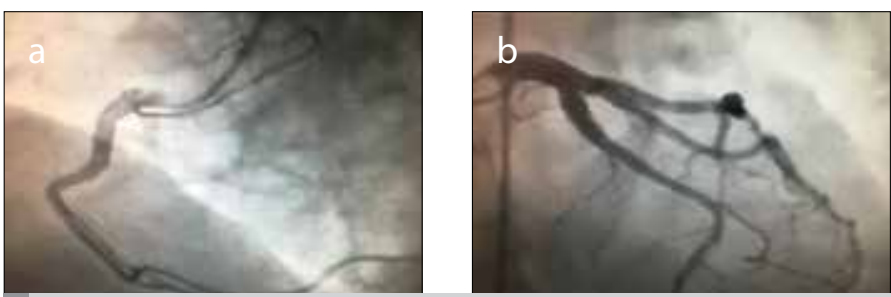

FIGURE 2. a, b. Coronary angiogram showing normal right (a) and left (b) coronary arteries

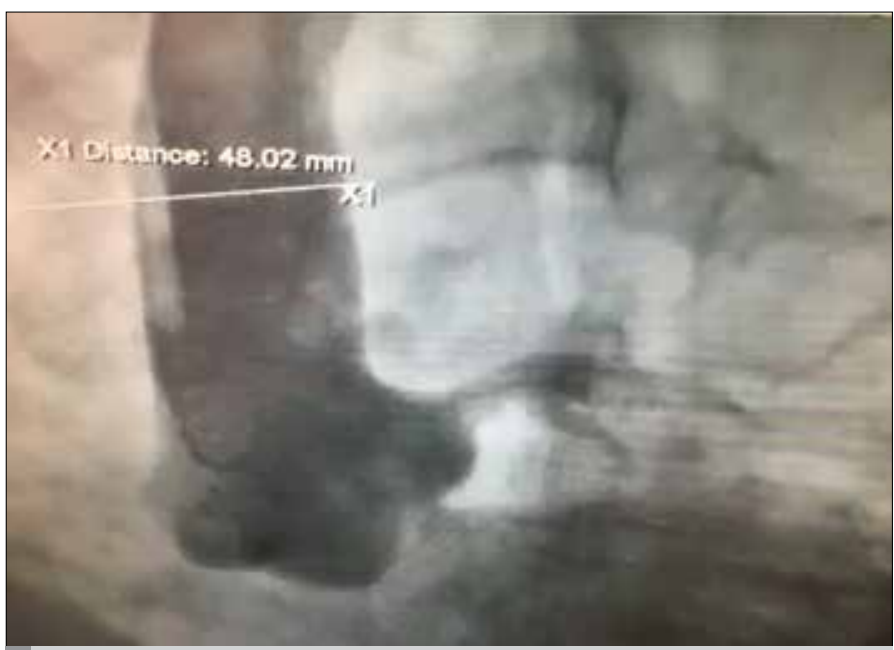

FIGURE 3. Aortagram showing dissection of the ascending aorta

\section{Discussion}

Acute aortic dissection is the most common life-threatening disorder affecting the aorta, with an estimated annual incidence of approximately 5 to 30 per million (2). The early mortality rate in cases of acute aortic dissection is very high, with an hourly mortality rate of up to $1 \%-2 \%$ being reported in the first several hours after dissection (3).

There are two major classification schemes of aortic dissection, based on the location of the dissection: DeBakey and Stanford classifications. Stanford type A dissections involve the ascending aorta and type B dissections occur distal to the subclavian artery (4). On the other hand, in the DeBakey classification, type 1 dissections begin in the ascending aorta and extend to the descending one, while type 2 dissections involve the ascending aorta only and type 3 dissections begin in the descending aorta distal to the left subclavian artery (5). The treatment depends on the site, with emergency surgery being recommended for acute type A dissections and initial medical therapy being recommended for type B dissections.
The symptoms of aortic dissection can vary and may mimic those of more common conditions, emphasizing the importance of a high index of suspicion. The most common symptom of acute aortic dissection is pain (2), but painless aortic dissection has been reported in $6 \%$ of patients in one study (6). However, patients may present with symptoms related to AD complications, such as heart failure, acute stroke, syncope, acute myocardial infarction, ischemic peripheral neuropathy, paraplegia, and cardiac arrest or sudden death. These symptoms are often associated with occlusion of distal branch arteries by the dissection flap (7). Pathophysiological mechanisms of a branch vessel compromise associated with aortic dissection could be explained by the location where the expanding hematome causes narrowing of the affected vessel and the location where the dissection flap can partially occlude the ostium of an artery, affecting the blood flow inside the vessel (8). In addition, the dissection can directly extend into the coronary arteries from the aorta, and usually, the right coronary artery is affected more often than the left one (9).

In our patient, aortic dissection was diagnosed after the patient underwent coronary angiography. Coronary angiography showed normal coronary arteries. Myocardial infarction most likely resulted from functional coronary artery occlusion due to aortic dissection, in which the dissection flap temporarily occluded the ostium of the right coronary artery and affected the blood flow to the vessel.

In addition, in our case, aortic dissection extended to the brachiocephalic trunk, closing down and occluding the ostium of the right subclavian artery. Our patient had upper extremity pain, intermittent pulse deficits, and pseudohypotension that may be due to right subclavian artery occlusion.

In the literature, there have been few cases of ascending aortic dissections presenting with STEMI complicating right subclavian artery occlusion (10). However, our case mimics inferior myocardial infarction and complicating right subclavian artery occlusion and exhibits correlated symptoms and findings.

\section{Conclusion}

In conclusion, aortic dissection has still been frequently misdiagnosed as acute coronary syndrome. Aortic dissection should always be considered in the differential diagnosis of patients presenting with acute infarction, particularly inferior infarction, especially when their risk factors, symptoms, or examination findings are compatible with this diagnosis.

Informed Consent: Written informed consent was obtained from patient who participated in this study.

Peer-review: Externally peer-reviewed.

Author contributions: Concept - A.D., H.S.; Design - M.T.Ö., A.D.; Supervision - W.S., M.T.; Resource - M.T.Ö., A.D.; Materials - W.S., H.S.; Data Collection and/ or Processing -W.S., M.T.; Analysis and/or Interpretation - A.D., H.S.; Literature Search - M.T.Ö., A.D.; Writing - M.T.Ö., A.D.; Critical Reviews - H.S.

Conflict of Interest: No conflict of interest was declared by the authors.

Financial Disclosure: The authors declared that this study has received no financial support. 


\section{References}

1. Spittell PC, Spittell JA Jr, Joyce JW, Tajik AJ, Edwards WD, Schaff HV, et al. Clinical features and differential diagnosis of aortic dissection: experience with 236 cases (1980 through 1990). Mayo Clin Proc 1993; 68: 642-51. [CrossRef]

2. Hagan PG, Nienaber CA, Isselbacher EM, Bruckman D, Karavite DJ, Russman PL, et al. International Registry of Acute Aortic Dissection (IRAD): New insights from an old disease. JAMA 283: 897-9003. [CrossRef]

3. Hirst AE Jr, Johns VJ Jr, Kime SW Jr: Dissecting aneurysm of the aorta: A review of 505 cases. Medicine (Baltimore) 1958; 37: 217-79. [CrossRef]

4. Daily PO, Trueblood HW, Stinson EB, Wuerflein RD, Shumway NE. Management of acute aortic dissections. Ann Thorac Surg 1970; 10: 237-47. [CrossRef]

5. Debakey ME, Henly WS, Cooley DA, Morris GC Jr, Crawford ES, Beall AC Jr. Surgical management of dissecting aneurysms of the aorta. JThorac Cardiovasc Surg 1965; 49: 130-49.
6. Park SW, Hutchison S, Mehta RH, Isselbacher EM, Cooper JV, Fang J, et al. Association of painless aortic dissection with increased mortality. Mayo Clin Proc 2004; 79: 1252-7. [CrossRef]

7. Matsumura JS, Cambria RP, Dake MD, Moore RD, Svensson LG, Snyder S, et al. International controlled clinical trial of the thoracic endovascular aneurysm repair with the Zenith TX2 endovascular graft: 1 year results. J Vasc Surg 2008; 47: 247-57. [CrossRef]

8. Erbel R, Alfonso F, Boileau C, Dirsch O, Eber B, Haverich A, et al. Diagnosis and management of aortic dissection. Eur Heart J 2001; 22: 1642-81. [CrossRef]

9. Lars G. Svensson E, Stanly C. Aortic dissection in cardiovascular and vascular disease of the aorta. WB. Saunders Company Philadelphia 1997; 42-83.

10. Koushima R, Kikuchi Y, Sakurada T, Kusajima K. A case of painless Standford type A acute aortic dissection complicating acute occlusion of the right subclavian artery. Kyobu Geka 1998; 51: 226-30. 